\title{
FTY720 enhances osteogenic differentiation of bone marrow mesenchymal stem cells in ovariectomized rats
}

\author{
CHUANG HUANG ${ }^{1,2^{*}}$, RUI LING ${ }^{3 *}$, FEI-JIANG LI ${ }^{4}$, ER-CUI LI ${ }^{5}$, QI-KE HUANG ${ }^{3}$, \\ BAO-GANG LIU ${ }^{6}$, YIN DING ${ }^{1}$ and SI-WEI YOU ${ }^{2}$ \\ ${ }^{1}$ Department of Orthodontics, State Key Laboratory of Military Stomatology, School of Stomatology; \\ ${ }^{2}$ Department of Ophthalmology, Xijing Hospital; ${ }^{3}$ Department of General Surgery, Xijing Hospital; \\ ${ }^{4}$ Department of Biomedical Engineering, The Fourth Military Medical University; \\ ${ }^{5}$ Department of Gastroenterology and Endocrinology, Shaanxi Provincial Armed Police Corps Hospital, \\ Xi'an, Shaanxi 710032; ${ }^{6}$ Out-Patient Department, General Hospital of The Second Artillery, \\ Beijing 100820, P.R. China
}

Received July 7, 2015; Accepted May 10, 2016

DOI: $10.3892 / \mathrm{mmr} .2016 .5342$

\begin{abstract}
Sphingosine-1-phosphate and its structural analog FTY720 (fingolimod) are important in the inhibition of osteoclast differentiation and bone resorption, however, it remains unknown whether they enhance osteogenic differentiation of the bone marrow mesenchymal stem cells (BM-MSCs). The present study investigated the effect of FTY720 on the osteogenic differentiation of BM-MSCs from the femurs of the ovariectomized $(\mathrm{OVX})$ rats. Three different concentrations (1, 10 and $100 \mathrm{nM}$ ) of FTY720 were demonstrated to markedly upregulate mRNA expression levels of Runt-related transcription factor 2 (Runx2) and $\mathrm{Sp} 7$ transcription factor (Sp7) at 2 weeks, and alkaline phosphatase (ALP) at 3 weeks. The osteocalcin $(\mathrm{OCN})$ expression was similar at weeks 2 and 3. The protein expression levels of Runx2, Sp7, OCN and ALP induced by three different concentrations of FTY720 were higher than those in the control groups at 3 weeks in the OVX and sham groups. The findings of the current study suggested a beneficial effect of FTY720 on bone formation in OVX rats, and provided a potential therapeutic method of
\end{abstract}

Correspondence to: Professor Yin Ding, Department of Orthodontics, State Key Laboratory of Military Stomatology, School of Stomatology, The Fourth Military Medical University, 169 Changlexi Road, Xi'an, Shaanxi 710032, P.R. China

E-mail: dingyin_fmmu_cn@163.com

Professor Si-Wei You, Department of Ophthalmology, Xijing Hospital, The Fourth Military Medical University, 169 Changlexi Road, Xi'an, Shaanxi 710032, P.R. China

E-mail: yousiwei_fmmu@126.com

*Contributed equally

Key words: sphingosine-1-phosphate, FTY720, post-menopausal osteoporosis, ovariectomy, osteogenic differentiation
FTY720 to prevent alveolar bone resorption in patients with post-menopausal osteoporosis.

\section{Introduction}

Estrogen deficiency commonly occurs in post-menopausal women and results in systemic osteoporosis. Osteoporosis is characterized by decreased bone mineral density (BMD) and microarchitectural deterioration of bone, due to increased bone resorption compared with formation. Thus, osteoporosis has become one of the most prevalent and complex skeletal disorders for post-menopausal women, the aged and those with other associated medical conditions, or those who develop the condition as a result of certain therapeutic interventions $(1,2)$.

A positive association has also been observed between post-menopausal osteoporosis (PMO) and periodontitis. The treatment of osteoporosis, particularly of osteoporosis with loss of alveolar crestal height, remains key (3). Sphingosine-1-phosphate (S1P) is formed by phosphorylation of sphingosine catalyzed by sphingosine kinases (two isozymes designated sphingosine kinase 1 and sphingosine kinase 2), and it has previously been recognized as an important coupling molecule of osteoclast and osteoblast activity that results in osteoanabolic effects (4-6). S1P is pleiotropic, autocrine- and paracrine-signaling sphingolipid released into the blood upon platelet activation. It binds to a family of five high affinity $\mathrm{G}$-coupled receptors [sphingosine 1 phosphate receptor $(\mathrm{S} 1 \mathrm{P}) ; \mathrm{S}_{1} \mathrm{P}_{1}-\mathrm{S}_{1} \mathrm{P}_{5}$ ] and results in a wide range of biological processes, including the stimulation of osteoblast migration and promotion of mature cell survival during endogenous bone wound healing (7). S1P inhibits the differentiation of osteoclast precursors to mature osteoclasts (5), and regulates osteoclast-osteoblast coupling (7). S1P also enhances the survival and migration of osteoblasts (7). Thus, S1P may be a potential strategy to support bone formation in PMO and in fracture repair. FTY720 (fingolimod) is isolated from a Chinese herb and exerts immunomodulating activity (8). It has been demonstrated to be a $\mathrm{S} 1 \mathrm{P}$ receptor agonist (for $\mathrm{S}_{1} \mathrm{P}_{1}$ and 
$\mathrm{S} \mathrm{P}_{3-5}$ receptors). Compared with native S1P (half life $=2 \mathrm{~h}$ ) (9) and BMP-2 ligand (half life =16 min) (10), FTY720 has a longer systemic half-life (20 h) (11) and increased physiological stability for clinical applications. S1P and FTY720 are important role in numerous tissue-repairing processes, including bone regeneration, improvement of microvascular remodeling, and osseous tissue growth in vivo (12-14). However, whether S1P and FTY720 could enhance osteogenic differentiation of bone marrow mesenchymal stem cells (BM-MSCs) remains to be elucidated.

The ovariectomized (OVX) rat exhibits the majority of the characteristics of human PMO, and this animal model has been ratified by the United States Food and Drug Administration as the primary model to evaluate the prevention and treatment of PMO $(15,16)$. In the present study, BM-MSCs were collected from femurs of the OVX rats. Following induction of osteogenic differentiation with different concentrations of FTY720, the stimulating effects of FTY720 on the BM-MSCs were evaluated. The results of the present study demonstrated that FTY720 may enhance the bone-forming ability of the BM-MSCs derived from OVX and sham rats. In addition, the impaired bone-forming ability of the BM-MSCs derived from OVX rats, due to estrogen deficiency, was partly repaired following administration of FTY720.

\section{Materials and methods}

Animals and surgical procedures. Female Sprague-Dawley rats $(n=40$; age, 12 weeks; weight, $240 \pm 20 \mathrm{~g}$ ) were purchased from the Laboratory Animal Research Center of the Fourth Military Medical University (Xi'an, China) and all interventions were performed in full accordance with the National Institutes of Health Guidelines for the Care and Use of Laboratory Animals (17). The rats were housed one per cage in a room exposed to artificial 12/12-h light-dark cycles at $24 \pm 2^{\circ} \mathrm{C}$ with $60 \pm 20 \%$ relative humidity. All animals were fed $15 \mathrm{~g}$ of a rodent diet containing $0.3 \%$ calcium and deionized water ad libitum per day to prevent weight gain in OVX rats as recommended by Sims et al (18). The study was approved by the ethics committee of the Fourth Military Medical University.

Following one week for acclimatizing to the new laboratory surroundings, the rats were randomly divided into experimental OVX and sham surgery control groups ( $n=20 /$ group). All the animals were anesthetized with an intraperitoneal injection of $8 \%$ chloral hydrate solution $(6 \mathrm{ml} / \mathrm{kg}$ body weight). Bilateral ovariectomy was performed in 20 rats in the OVX group under sterile conditions as previously described (19). The remaining 20 rats had their ovaries surgically exteriorized and replaced in sham surgery control group.

Micro-computed tomography (CT) measurement. Retrieved femoral samples of the animals in the OVX and sham groups were scanned with a micro-CT scanner (SCANCO Medical AG, Brüttisellen, Switzerland) 12 weeks after the surgery to ensure that the PMO animal model was established successfully (20). The scanner was operated at $70 \mathrm{kV}, 145 \mu \mathrm{A}, 300 \mathrm{msec}$ integration time, 500 projections on $360^{\circ}, 1024 \mathrm{CCD}$ detector array and $8.6 \mu \mathrm{m} /$ pixel for scan resolution. Trabecular bone parameters were calculated using the SCANCO Medical microCT systems for scanning, 3D analysis, visualization, image management and data import/export (SCANCO Medical AG). Morphometric indices of the trabecular bone region were determined from microtomographic data sets using direct three-dimensional morphometry. The microarchitecture parameters of BMD, trabecular thickness (Tb.Th) and bone volume/total volume ratio (BV/TV, bone volume fraction) were assessed.

Isolation and culture of rat BM-MSCs (rBM-MSCs). Following ovariectomy (after 12 weeks), the OVX and control rats were sacrificed using sodium pentobarbital at a dose of $>60 \mathrm{mg} / \mathrm{kg}$ (Sigma-Aldrich St. Louis, MO, USA). Bilateral femurs were harvested under aseptic conditions and all soft tissues were removed. Metaphysis from the two ends of the femurs were removed. The marrow was flushed out with $10 \mathrm{ml}$ Dulbecco's modified Eagle's medium (DMEM, Gibco; Thermo Fisher Scientific, Inc., Waltham, MA, USA) and supplemented with $10 \%$ fetal bovine serum (FBS, Gibco; Thermo Fisher Scientific, Inc.) and penicillin $100 \mathrm{U} / \mathrm{ml}$ and streptomycin $100 \mu \mathrm{g} / \mathrm{ml}$ (Invitrogen; Thermo Fisher Scientific, Inc.). The cells were cultured at $37^{\circ} \mathrm{C}$ in a $5 \% \mathrm{CO}_{2}$ incubator for $\sim 2$ weeks, washed with phosphate buffered saline (PBS) and passaged with $0.25 \%$ trypsin/ethylenediaminetetraacetic acid (Gibco; Thermo Fisher Scientific, Inc.). The rBM-MSCs from passage 2 were used for treatment with different concentrations of FTY720 (Sigma-Aldrich).

Flow cytometry analysis. The surface markers of mesenchymal and non-mesenchymal stem cells are identifying characteristics of the immunophenotype of ex vivo-expanded rBM-MSCs. The expression levels of these markers were measured by flow cytometric analysis at passage 2 . Briefly, $\sim 1 \times 10^{6}$ liberated adherent cells were harvested and washed with PBS containing 3\% FBS in different Eppendorf tubes. The single-cell suspension was then resuspended and incubated with phycoerythrin-conjugated anti-rat antibodies as follows: Monoclonal armenian hamster cluster of differentiation (CD)29 (1:100; \#562154); and monoclonal mouse CD45 (1:100; \#554878); CD90 (1:100; \#551401); and CD106 (1:100; \#559229) obtained from BD Biosciences (Franklin Lakes, NJ, USA); and mouse monoclonal CD34 (1:50; \#ab187284) and CD44 (1:200; \#ab23396) from Abcam (Cambridge, UK), at $4^{\circ} \mathrm{C}$ in the dark. Cell suspension without antibodies served as a control to determine background fluorescence. The cells were washed three times after $1 \mathrm{~h}$ with PBS containing 3\% FBS and $300 \mu \mathrm{l}$ suspension was added to the testing tubes. Finally, the samples were measured by flow cytometric analysis using a Accuri C6 flow cytometer (BD Biosciences).

\section{3-(4,5-dimethylthiazol-2-yl)-2,5-diphenyl-2H-tetrazolium} bromide (MTT) assay. The MTT assay was performed to evaluate the proliferation of the OVX and sham passage 2 BM-MSCs separately incubated in basic medium (DMEM supplemented with $10 \% \mathrm{FBS}$ ). Briefly, cells were seeded in 96-well plates at $5 \times 10^{3}$ cells/well and cultured in a humidified atmosphere of $5 \% \mathrm{CO}_{2}$ at $37^{\circ} \mathrm{C}$ for $16 \mathrm{~h}$. The medium was then discarded and MTT (Amresco, LLC, Solon, OH, USA) solution was added. After $4 \mathrm{~h}$ incubation at $37^{\circ} \mathrm{C}$ in a $5 \% \mathrm{CO}_{2}, 200 \mu \mathrm{l}$ dimethyl sulfoxide (Sigma-Aldrich) was added and agitated for $15 \mathrm{~min}$ to dissolve the formazan crystals. The optical 
Table I. Primers used in the present study.

\begin{tabular}{|c|c|c|c|c|}
\hline Gene & Forward primer ( $5^{\prime}$ to $\left.3^{\prime}\right)$ & Reverse primer ( $5^{\prime}$ to $\left.3^{\prime}\right)$ & GenBank accession & Size (bp) \\
\hline Runx2 & ССТCTGACTTCTGCCTCTGG & GATGAAATGCCTGGGAACTG & NM_001278483 & 106 \\
\hline Sp7 & TTCACCTGTCTGCTCTGCTC & GCTGATTGGCTTCTTCTTCC & NM_181374 & 154 \\
\hline $\mathrm{OCN}$ & ACAAGTCCCACACAGCAACTC & CCAGGTCAGAGAGGCAGAAT & NM_013414 & 103 \\
\hline ALP & GGCTGGAGATGGACAAGTTC & ACGCCACACAAGTAGGCAGT & J03572 & 106 \\
\hline GAPDH & ACAGCAACAGGGTGGTGGAC & TTTGAGGGTGCAGCGAACTT & ВC059110 & 105 \\
\hline
\end{tabular}

Runx2, Runt-related transcription factor 2; Sp7, Sp7 transcription factor; OCN, osteocalcin; ALP, alkaline phosphatase.

density (OD) of the solution was measured at a wavelength $570 \mathrm{~nm}$ by ELx808 Absorbance Microplate Reader (BioTek Instruments, Inc., Winooski, VT, USA). The MTT assay, as described above, was performed once a day for 10 days.

Osteogenic differentiation induced by different concentrations of FTY720. To determine the effects of FTY720 at different concentrations, $0,1,10$ and $100 \mathrm{nM}$ were selected in preliminary experiments and $0 \mathrm{nM}$ served as a control. rBM-MSCs from the OVX and sham groups were seeded in 24-well tissue culture plates at a density of $1 \times 10^{6}$ cells $/ \mathrm{ml} /$ well and divided into 8 groups: i) OVX rBM-MSCs without FTY720 (0 nM, blank control); ii) sham rBM-MSCs without FTY720 (0 nM, control); iii) OVX rBM-MSCs with 1 nM FTY720; iv) sham rBM-MSCs with 1 nM FTY720; v) OVX rBM-MSCs with 10 nM FTY720; vi) sham rBM-MSCs with 10 nM FTY720; vii) OVX rBM-MSCs with $100 \mathrm{nM}$ FTY720; and viii) sham rBM-MSCs with 100 nM FTY720.

Following grouping, FTY720 was added to the osteogenic differentiation medium $[10 \% \mathrm{v} / \mathrm{v}$ FBS, DMEM, $10 \mathrm{nM}$ dexamethasone, $10 \mathrm{mM}$ sodium $\beta$-glycerophosphate (Sigma-Aldrich), $50 \mu \mathrm{g} / \mathrm{ml}$ vitamin C (Gibco; Thermo Fisher Scientific, Inc.), $100 \mathrm{U} / 1$ penicillin and $100 \mathrm{U} / 1$ streptomycin]. The cells were allowed to reach $80 \%$ confluency, and then osteogenesis was initiated with osteogenic differentiation medium containing $0,1,10$ or $100 \mathrm{nM}$ FTY720. The medium was changed every 3 days.

Reverse transcription-quantitative polymerase chain reaction $(R T-q P C R)$. The cells were incubated at $37^{\circ} \mathrm{C}$ in $5 \% \mathrm{CO}_{2}$ and harvested to assess mRNA expression levels at 1,2 and 3 weeks. The relative gene expression levels of Runt-related transcription factor 2 (Runx2), Sp7 transcription factor (Sp7, also termed osterix), osteocalcin (OCN) and alkaline phosphatase (ALP) in rBM-MSCs were compared among the 8 groups to detect the extracellular matrix and genes of the osteogenesis marker. Total RNA was purified from the cells using TRIzol reagent (Invitrogen; Thermo Fisher Scientific, Inc.) according to the manufacturer's protocols. For reverse transcription of mRNA and the PCR reaction system, conditions and analysis method were used as described previously (20). The first-strand cDNAs were synthesized from $5 \mu \mathrm{g}$ total RNA using ReverTra Ace qPCR RT Master Mix with gDNA Remover (Toyobo Co., Ltd., Osaka, Japan) as follows: Genomic DNA removal (degradation), $37^{\circ} \mathrm{C}$ for $5 \mathrm{~min}$; cDNA synthesis, $37^{\circ} \mathrm{C}$ for $15 \mathrm{~min}$; reverse transcriptase inactivation reaction, $98^{\circ} \mathrm{C}$ for $5 \mathrm{~min}$; total time, $\sim 30 \mathrm{~min}$. A DNase step was performed to dissociate the irrelevant DNA prior to qPCR. DNase I from the RT kit was used in the present experiment. RT-qPCR was performed using a SYBR Green PCR Master Mix (Applied Biosystems; Thermo Fisher Scientific, Inc.) and a GeneAmp 9700 thermal cycler (Applied Biosystems; Thermo Fisher Scientific, Inc.). The following PCR conditions were used: $95^{\circ} \mathrm{C}$ for $10 \mathrm{sec}$; 40 cycles of $95^{\circ} \mathrm{C}$ for $5 \mathrm{sec}$ and $60^{\circ} \mathrm{C}$ for $30 \mathrm{sec}$; and dissociation program of $95^{\circ} \mathrm{C}$ for $15 \mathrm{sec}, 60^{\circ} \mathrm{C}$ for $30 \mathrm{sec}$, and $95^{\circ} \mathrm{C}$ for $15 \mathrm{sec}$. GAPDH served as an internal control. The expression levels of the target genes were calculated from $\Delta \Delta \mathrm{Cq}$ values (21). Primers for the RT-qPCR were synthesized by Shanghai Shenggong Biology Engineering Technology Service, Ltd. (Shanghai, China) based on the GenBank database (www.ncbi.nlm.nih.gov/genbank). The primer sequences are listed in Table I.

Western blot analysis. Protein expression levels of Runx2, $\mathrm{Sp} 7, \mathrm{OCN}$ and ALP were detected by western blot analysis 3 weeks after induction of osteogenic differentiation. Cells were washed with cold PBS (pH 7.0) and the whole cell-aggregate lysates were extracted by radioimmunoprecipitation assay buffer (Beyotime Institute of Biotechnology, Haimen, China) containing $50 \mathrm{mM}$ Tris ( $\mathrm{pH} 7.4), 150 \mathrm{mM} \mathrm{NaCl}, 1 \%$ Triton $\mathrm{X}-100,1 \%$ sodium deoxycholate and $0.1 \%$ sodium dodecyl sulfate (SDS) with a protease inhibitor cocktail (Sigma-Aldrich). The concentration of total protein was determined with a bicinchoninic acid assay (Beyotime Institute of Biotechnology) following the manufacturer's protocol. Briefly, the protein samples were loaded on $12 \%$ SDS-PAGE gels and, following electrophoresis, transferred onto polyvinylidene difluoride membranes (EMD Millipore, Billerica, MA, USA) at $100 \mathrm{~V}$ for $1.5 \mathrm{~h}$. Following blocking with $5 \%$ bovine serum albumin (Gibco; Thermo Fisher Scientific, Inc.) at room temperature for $2 \mathrm{~h}$, the membranes were incubated with primary antibodies purchased from Abcam overnight at $4^{\circ} \mathrm{C}$ as follows: Rabbit polyclonal Runx2 (1:1,000; \#ab23981); rabbit monoclonal Sp7 (1:2,000; \#ab187158); mouse monoclonal OCN (1:500; \#ab13418); rabbit polyclonal ALP (1:1,000; \#ab95462); and rabbit polyclonal GAPDH (1:2,500; ab9485), followed by incubation with corresponding secondary antibodies from Abcam as follows: Horseradish peroxidase-conjugated goat polyclonal anti-rabbit (1:20,000; \#ab97051) and anti-mouse (1:10,000; \#ab6789) IgGs. The bands were visualized using the eEcl Western Blot kit (CWBIO, Ltd., Beijing, China) and were quantified using ImageQuant TL 7.0 Image Analysis Software (GE Healthcare Life Sciences, Pittsburgh, PA, USA). 
A

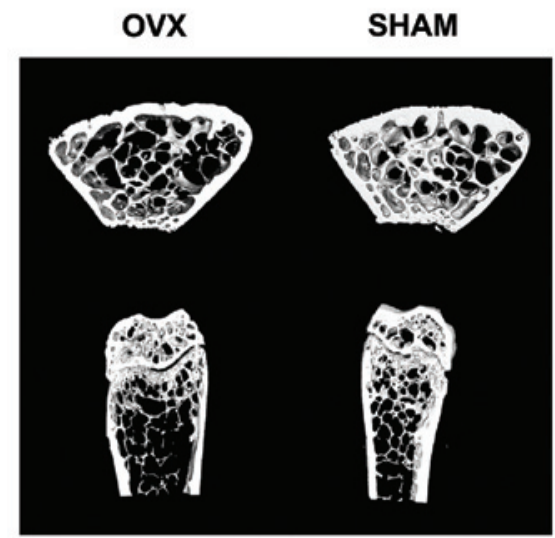

C

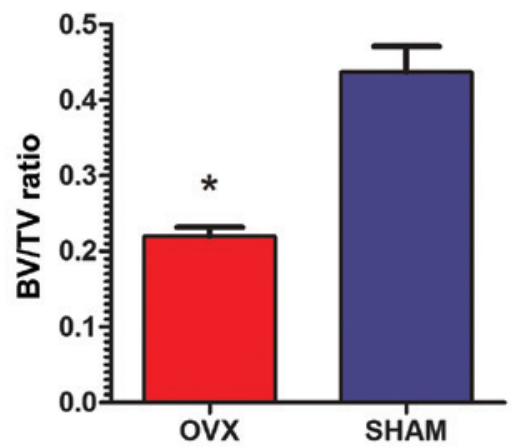

B

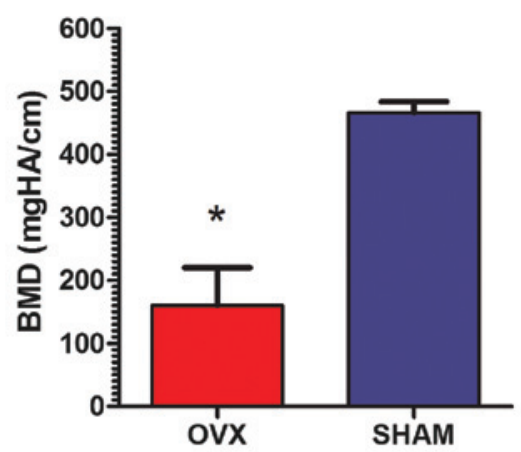

D

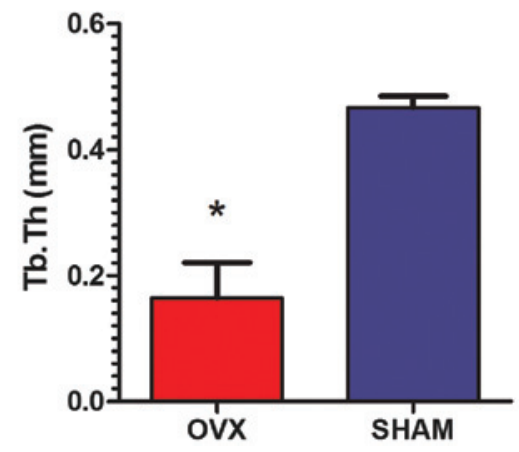

Figure 1. Micro-computed tomography evaluation of the proximal tibiae 12 weeks after surgery. (A) The features of normal bone observed in sham rats were markedly changed in OVX rats. Morphometric analysis demonstrated that (B) the local BMD, (C) BV/TV and (D) Tb.Th in the proximal tibia were significantly decreased in OVX-group. "P<0.01 vs. the sham group. OVX, ovariectomized; BMD, bone mineral density; BV, bone volume; TV, total volume; Tb.Th, trabecular thickness.

Statistical analysis. Results are expressed as the mean \pm standard error of the mean. Differences between values were analyzed statistically using Student's t-test, one-way analysis of variance with Student-Newman-Keuls post-hoc test (GraphPad Prism 5.0; GraphPad Software, Inc., La Jolla, USA). P<0.05 was considered to indicate a statistically significant difference.

\section{Results}

The animal model was successfully generated. All rats remained healthy 3 months after surgery. Micro-CT validation of all rats demonstrated essential structures of the normal tibiae in the rats from the sham group, while the proximal tibiae were observed to be thinner and sparser in OVX rats (Fig. 1A). The micromorphology of the tibiae in the sham group rats was characterized by significantly higher BMD $(466.0 \pm 8.90 \mathrm{mgHA} / \mathrm{cm})$ compared with that in OVX rats $(160.1 \pm 30.08 \mathrm{mgHA} / \mathrm{cm} ; \mathrm{P}<0.01$; Fig. $1 \mathrm{~B})$. Increased $\mathrm{BV} / \mathrm{TV}$ was also observed in the sham group $(43.69 \pm 1.7 \%)$ compared with the OVX group (21.98 $\pm 0.6 \%$; $\mathrm{P}<0.01$; Fig. 1C). Furthermore, the $\mathrm{Tb} . \mathrm{Th}$ in the rats from the sham group $(0.467 \pm 0.009 \mathrm{~mm})$ was significantly higher than the OVX rats (0.164 \pm 0.028 mm; P<0.01; Fig. 1D).

rBM-MSCs from the OVX and sham groups were determined to be similar. The rBM-MSCs derived from OVX and sham group rats demonstrated similar expression of surface markers.
The cells were positive for CD29, CD44, CD90 and CD106, as demonstrated by the detection of 79.2\% CD29-, CD44-, CD90and CD106-positive rBM-MSCs. However, 4.62\% CD34- and CD45-positive rBM-MSCs were observed, suggesting the cells are negative for CD34 and CD45 (Fig. 2A). These results were compatible with the characteristics of stem cells proposed in previous studies $(22,23)$.

In vitro self-renewal potential of $r B M-M S C$ s increased in the OVX rBM-MSCs. The MTT assay indicated a higher proliferating ability of rBM-MSCs in the OVX group compared with the sham group (Fig. 2B). rBM-MSCs cultured in basic medium were predominantly fusiform, asteroid, triangle or polygonal with abundant cytoplasm and large, round or ovoid nucleoli. For the first 3 days, there was no significant difference in the OD values of rBM-MSCs in basic medium from the OVX group compared with the sham group $(\mathrm{P}>0.05)$, however, after day 4 , the OD values of cultured rBM-MSCs significantly increased in OVX group compared with those in sham group in a time-dependent manner $(\mathrm{P}<0.05)$. Notably, rBM-MSCs from the OVX group are more proliferative than rBM-MSCs from the sham group.

FTY720 alters osteogenic gene expression in rBM-MSCs. The primer sequences were based on data from GenBank (Table I). The mRNA expression levels of osteogenesis-associated genes, including Runx2, Sp7, OCN and ALP were examined at 1,2 and 


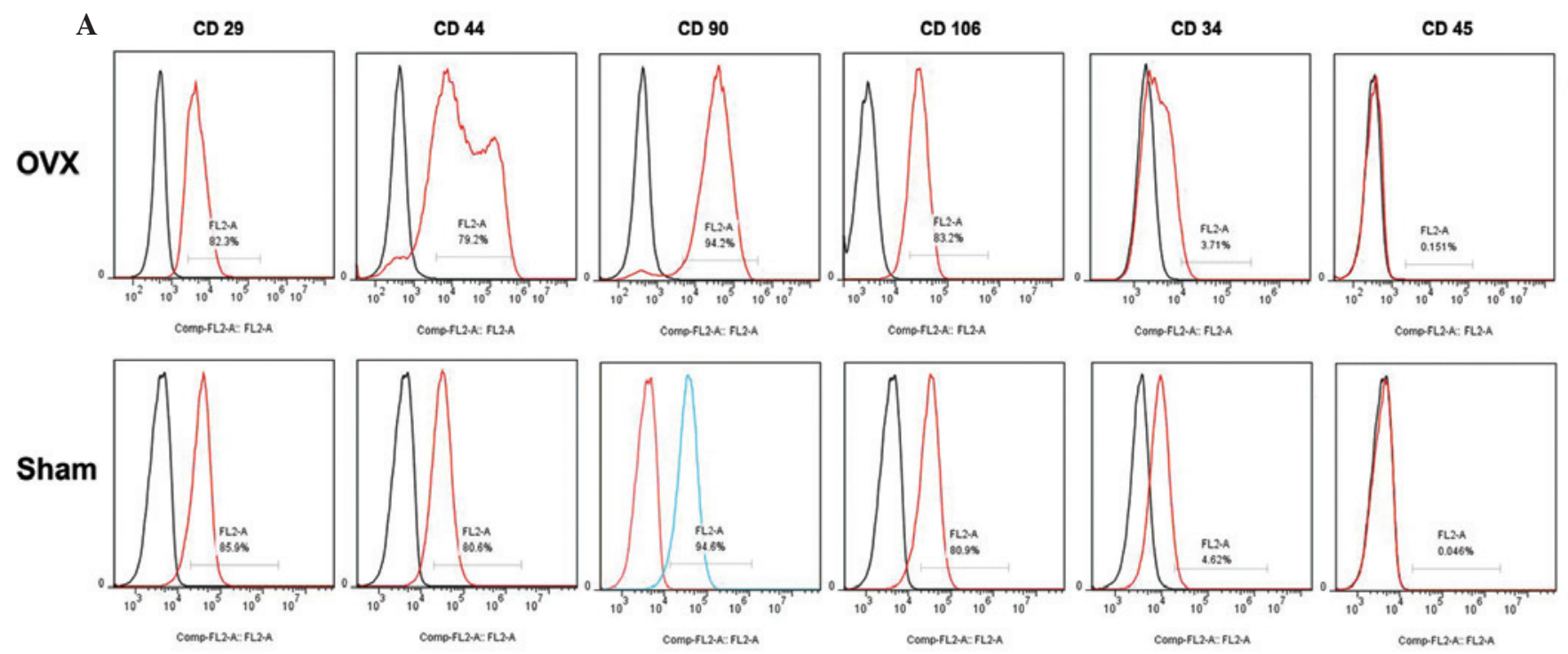

B

MTT assay

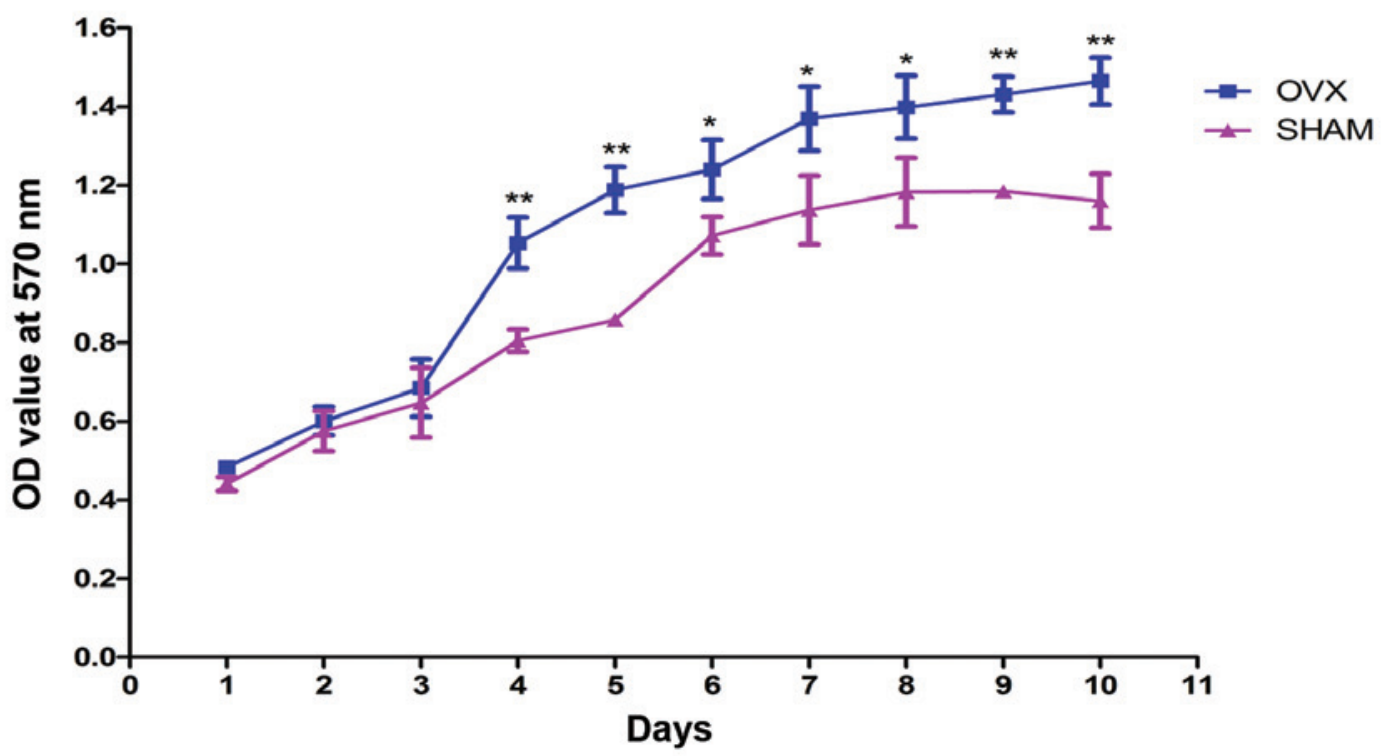

Figure 2. Characterization of rBM-MSCs and analysis of proliferation. (A) rBM-MSCs harvested from the OVX and sham groups were positive for mesenchymal stem cell-like markers, including CD29 (OVX=82.3\%; sham=85.9\%), CD44 (OVX=79.2\%; sham=80.6\%), CD90 (OVX=94.2\%; sham=94.6\%) and CD106 (OVX=83.2\%; sham=80.9\%), while these cells were negative for hematopoietic markers, including CD34 (OVX=3.71\%; sham=4.62\%) and $\mathrm{CD} 45$ $(\mathrm{OVX}=0.151 \%$; sham $=0.046 \%)$. (B) For the first 3 days, no significant difference was detected in the OD values of rBM-MSCs between the OVX and sham groups. From the 4 th day, the OD values of rBM-MSCs increased and increased cell proliferation was observed in the OVX group. ${ }^{*} \mathrm{P}<0.05,{ }^{* *} \mathrm{P}<0.01$ vs. the sham group. rBM-MSCs, rat bone marrow mesenchymal stem cells; OVX, ovariectomized; CD, cluster of differentiation; OD, optical density.

3 weeks (Fig. 3). Compared with the control groups cultured in

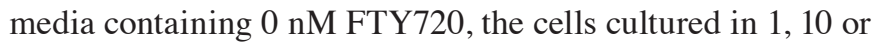
100 nM FTY720 demonstrated significantly increased expression levels $(\mathrm{P}<0.01)$ of Runx 2 and $\mathrm{Sp} 7$ at 2 weeks, and ALP at 3 weeks. The expression levels of OCN cultured in 1, 10 or $100 \mathrm{nM}$ was significantly increased $(\mathrm{P}<0.01)$ at 2 and 3 weeks compared with the results observed at 1 week. Furthermore, among the three concentrations, experimental groups treated with $10 \mathrm{nM}$ FTY720 exhibited significantly higher expression levels of Runx2 and Sp7 at 2 weeks, while ALP in the sham group was highest at 3 weeks. There was no significant difference $(\mathrm{P}>0.05)$ in expression of $\mathrm{OCN}$ at 2 and 3 weeks. The increased gene expression suggested an improved promotion of osteogenesis (24).
Notably, in contrast to OCN and ALP, the expression levels of Runx 2 and $\mathrm{Sp} 7$ in the OVX groups were significantly increased $(\mathrm{P}<0.05)$ compared with the sham group at 2 weeks, while ALP expression in sham groups increased to a higher level $(\mathrm{P}<0.05)$ than that in OVX group at 3 weeks. For the $10 \mathrm{nM}$ OVX sub-group, the highest expression levels of Runx2 and $\mathrm{Sp} 7$ were observed at 2 weeks $(\mathrm{P}<0.01)$ while the highest expression level of ALP was detected at 3 week $(\mathrm{P}<0.01)$. The expression levels of $\mathrm{OCN}$ were similar $(\mathrm{P}>0.05)$ at 2 and 3 weeks.

FTY720 alters osteogenic differentiation-associated protein expression in rBM-MSCs. The osteogenesis-associated protein expression levels of Runx2, Sp7, OCN and ALP with 
A

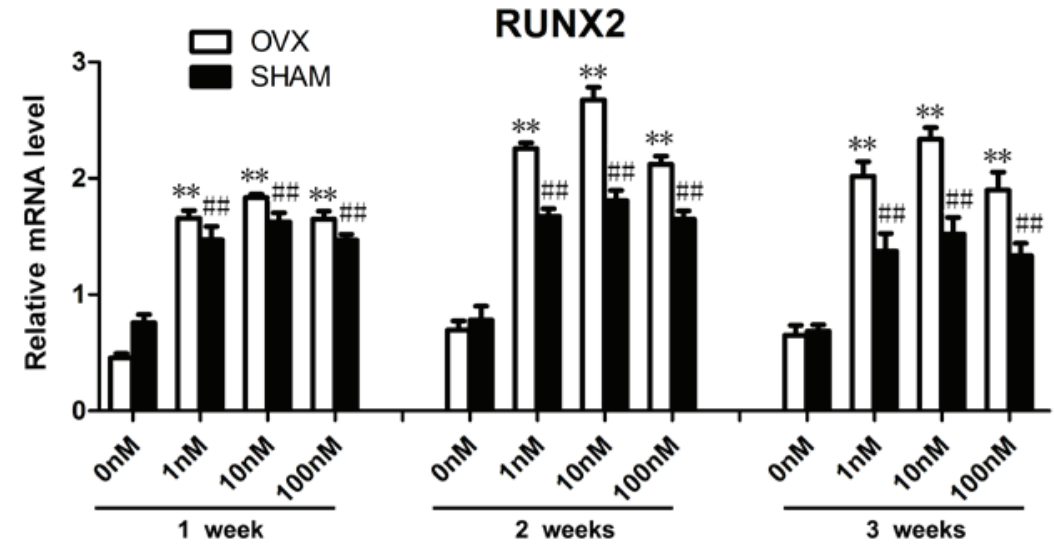

B

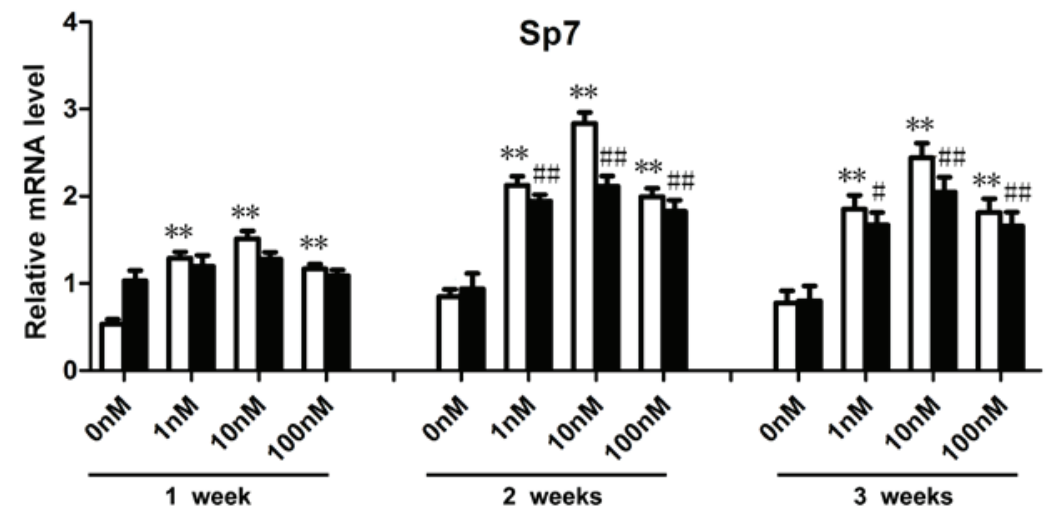

C

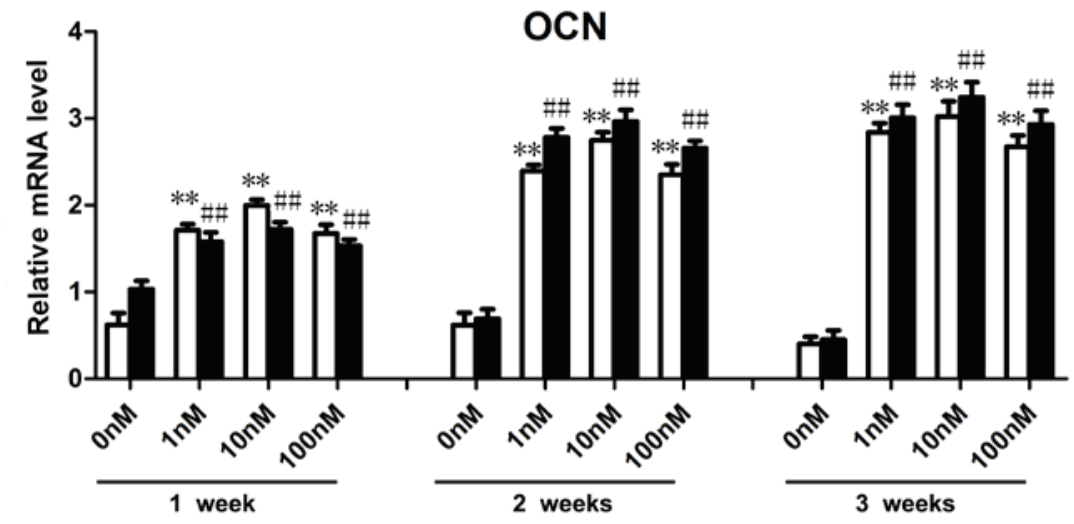

D

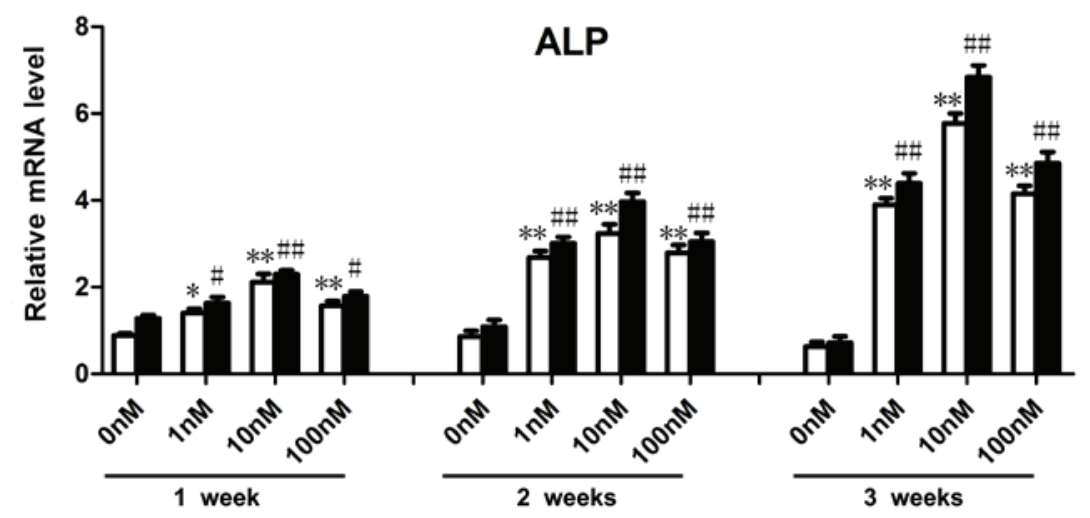

Figure 3. Osteogenic differentiation associated gene expression levels in rBM-MSCs treated with three different concentrations of FTY720 at 1, 2 and 3 weeks in OVX and sham Groups. (A and B) Runx2 and Sp7 mRNA expression levels increased with administration of 1, 10 or 100 nM FTY720 at 2 weeks, the highest expression levels were observed in the $10 \mathrm{nM}$ group at 2 weeks. The expression levels in the OVX groups were higher comapared with the sham groups at 2 weeks. (C) OCN mRNA expression levels significantly increased with 1, 10 and 100 nM FTY720 at 2 and 3 weeks. (D) ALP mRNA expression levels significantly increased with 1,10 or $100 \mathrm{nM}$ FTY720 at 3 weeks. The highest expression was observed in the $10 \mathrm{nM}$ group at 3 weeks. The mRNA expression levels of ALP in the OVX group were lower than those in the sham groups at 3 weeks. The mRNA expression levels were calculated as the fold expression relative to the control levels at the indicated time points. ${ }^{*} \mathrm{P}<0.05,{ }^{* *} \mathrm{P}<0.01 \mathrm{vs}$. the control in the OVX group. ${ }^{\#} \mathrm{P}<0.05$, ${ }^{\# \prime} \mathrm{P}<0.01$ vs. the control in the sham group. rBM-MSCs, rat bone marrow-mesenchymal stem cells; OVX, ovariectomized; RunX2, Runt-related transcription factor 2; Sp7, Sp7 transcription factor; OCN, osteocalcin; ALP, alkaline phosphatase. 

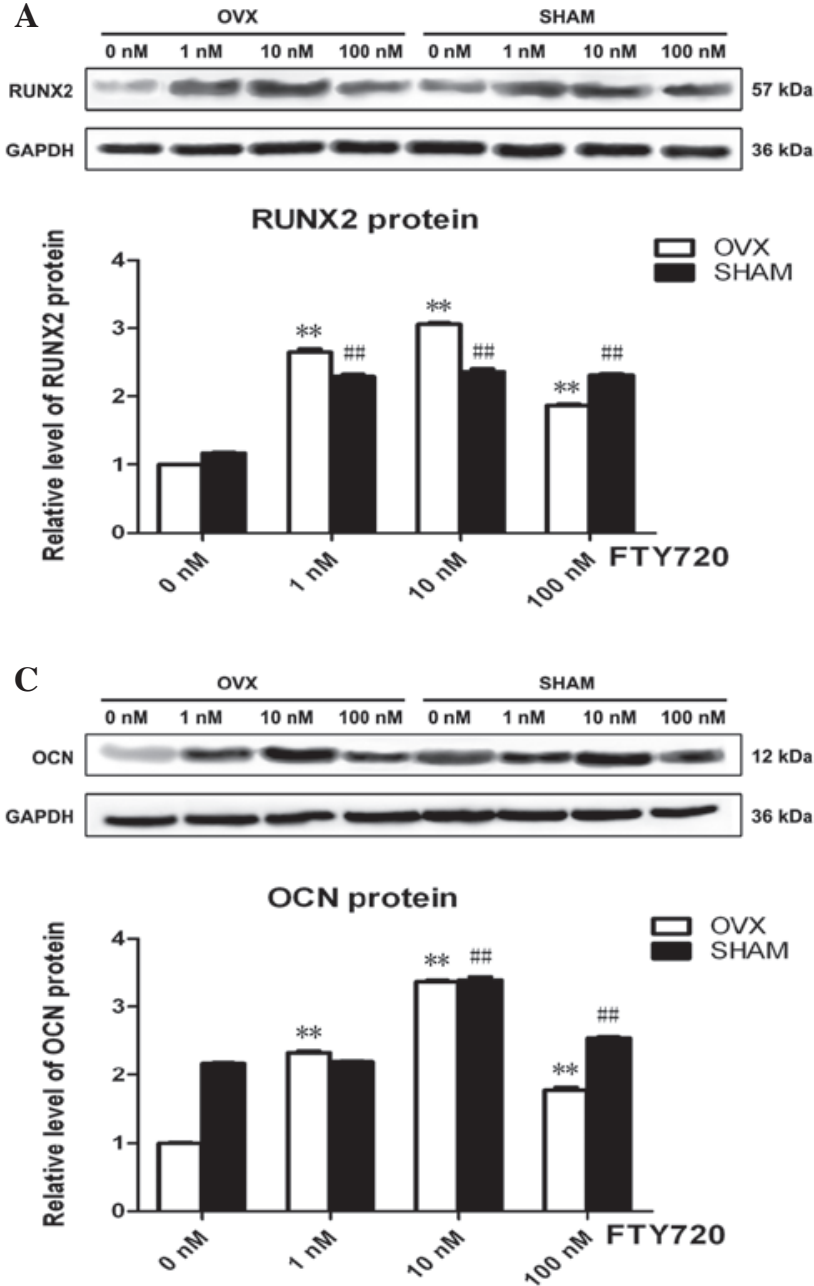

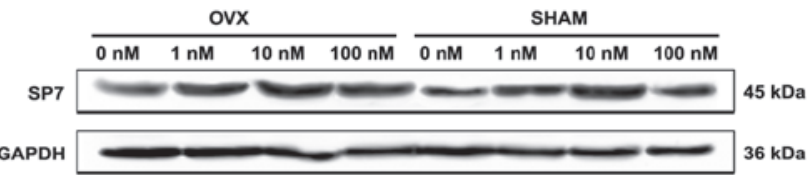

Sp7 protein

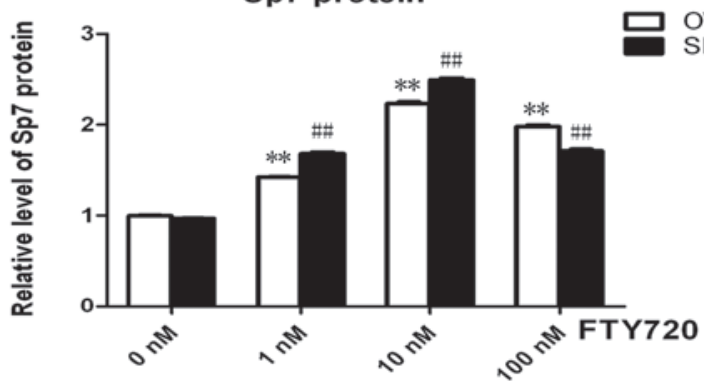

D

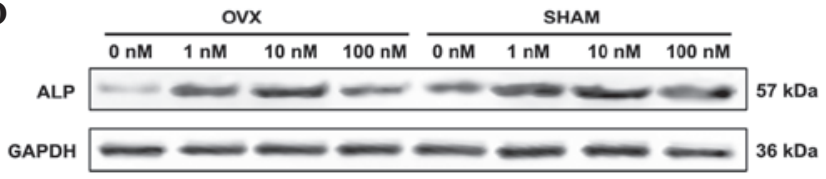

ALP protein

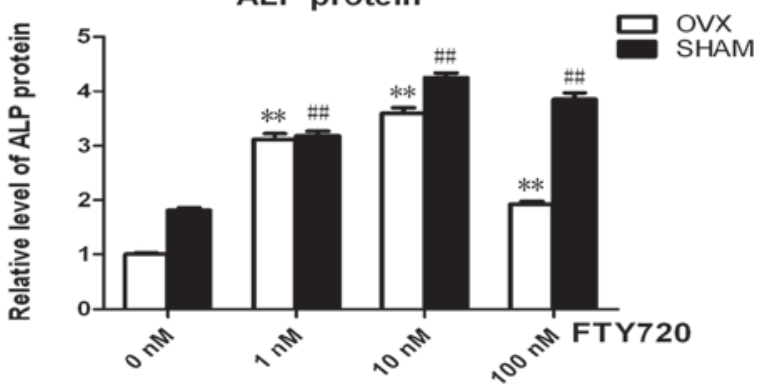

Figure 4. The expression profile of key proteins obtained from rBM-MSCs in the OVX and sham groups. The protein expression levels of (A) Runx2, (B) Sp7,

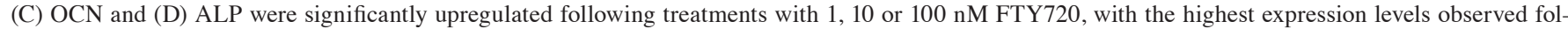
lowing $10 \mathrm{nM} \mathrm{FTY720} \mathrm{in} \mathrm{the} \mathrm{OVX} \mathrm{and} \mathrm{sham} \mathrm{groups.} \mathrm{Band} \mathrm{intensity} \mathrm{was} \mathrm{quantified} \mathrm{from} \mathrm{at} \mathrm{least} \mathrm{three} \mathrm{independent} \mathrm{experiments} \mathrm{and} \mathrm{calculated} \mathrm{as} \mathrm{the} \mathrm{fold}$ change in expression relative to the control levels. ${ }^{* *} \mathrm{P}<0.01 \mathrm{vs}$. the control in the OVX group. ${ }^{\# \#} \mathrm{P}<0.01 \mathrm{vs}$. the control in the sham group. rBM-MSCs, rat bone marrow-mesenchymal stem cells; OVX, ovariectomized; RunX2, Runt-related transcription factor 2; Sp7, Sp7 transcription factor; OCN, osteocalcin; ALP, alkaline phosphatase.

3 different concentrations of FTY720 in the osteogenic differentiation medium were significantly higher $(\mathrm{P}<0.01)$ than those with no FTY720 treatment ( $0 \mathrm{nM}$ control groups) at 3 weeks in the OVX and sham groups (Fig. 4). The experimental groups treated with $10 \mathrm{nM}$ FTY720 exhibited the highest protein expression levels of Runx2, Sp7, OCN and ALP $(\mathrm{P}<0.01)$, suggesting that $10 \mathrm{nM}$ FTY720 exerts the largest effect to promote osteogenesis (Fig. 4).

\section{Discussion}

Previous studies have demonstrated that S1P may result in osteoanabolic effects (4-6), and improve bone defect healing (12). The present study demonstrated that the S1P analog FTY720 promoted the expression of osteogenesis-associated genes and proteins, thus, inducing the osteogenic differentiation of rBM-MSCs from either OVX or sham rats. It was observed that FTY720 increased expression of markers for osteoblast differentiation, including ALP, OCN, Runx2 and Sp7 in rBM-MSCs from the OVX group. However, osteogenesis of rBM-MSCs from OVX rats was not induced without FTY720.
Thus, to the best of our knowledge, the current study is the first to demonstrate FTY720 induces osteoblast differentiation and mineralization by altering expression levels of osteogenesis-associated genes or proteins and osteoblast differentiation in rBM-MSCs from the OVX group.

It was recently reported that S1P modulates the differentiation of MSCs into cardiomyocytes and smooth muscle cells $(25,26)$. However, the effects of S1P or its analog FTY720 on osteoblast differentiation of BM-MSCs had not been elucidated. Furthermore, whether the osteogenic capability of BM-MSCs in osteoporosis could be recovered remained unknown. To increase understanding of the recovery of impaired bone healing ability in OVX rats, the evaluation of expression levels of genes and proteins associated with osteoblast differentiation, including ALP, OCN, Runx2 and Sp7, was performed. Runx2 is essential to osteoblast differentiation and osteogenesis, and regulates the expression of numerous extracellular matrix protein genes during differentiation (27). Similarly, ALP is an important marker of early osteoblast differentiation and the bone mineralization process (27). Furthermore, Sp7 is an osteoblast-specific transcription factor that activates a 
variety of genes during differentiation of preosteoblasts into mature osteoblasts and osteocytes (28). OCN, a 49 amino acid non-collagenous matrix protein of calcified tissue, is synthesized by osteoblasts. It has been hypothesized to be involved in bone resorption and mineralization, and is currently described as the most specific marker of mature osteoblasts (29). Thus, the present study aimed to elucidate the role of FTY720 on osteoblast differentiation in normal BM-MSCs (sham group) and BM-MSCs with osteoporosis (OVX group).

Previous studies have demonstrated that S1P or FTY720 induce differentiation of osteoblast-like cells, including the SaOS-2 (30), MC3T3-E1 (30), C2C12 (4), and C3H10T1/2 (31) cell lines into osteoblasts. Although these results are encouraging, clinical application requires further research. The findings of the present study regarding the effects of FTY720 for BM-MSC osteoblast differentiation suggest further research into clinical application should be conducted.

Notably, an abnormal result was detected in the present study. The gene expression levels of Runx2 and Sp7 in the OVX group were higher than those in sham group, however, the expression levels of ALP and OCN in the OVX group were lower than those in the sham group. Although the mechanism underlying this result remains unknown, it may be predicted that FTY720 is key in the process. It is well known that Runx2 and $\mathrm{Sp} 7$ are essential upstream transcription factors during the early processes of osteoblast differentiation (32). Kido et al (33) recently comparatively evaluated the process of bone repair in healthy and ovariectomized rats 14 days after tibial bone defect. It was hypothesized that ovariectomy-induced bone loss would suppress tissue healing, predominantly due to the decreased expression of genes and proteins associated with bone cell differentiation, and result in reduced formation of new bone. The RT-qPCR findings in the present study suggested that FTY720 may repair osteogenesis-associated gene expression, particularly the upstream transcription factors, such as Runx2 and $\mathrm{Sp} 7$, and thus promote bone regeneration.

It was also demonstrated that FTY720 increased gene and protein expression levels of ALP and OCN, the osteoblastic-specific phenotype markers secreted by mature osteoblasts. It has been reported that S1P is important in a number of tissue repairing processes, including bone regeneration. S1P or FTY720 improves microvascular remodeling and osseous tissue growth in vivo $(12,13)$. Thus, the present study hypothesized that FTY720 may be a potential therapeutic target for the promotion of bone regeneration.

In conclusion, all different concentrations of FTY720 administered to rBM-MSCs enhances osteogenic differentiation from either OVX or sham rats, and $10 \mathrm{nM}$ FTY720 induced the highest level of bone-associated gene expression in the present study. These findings suggested a beneficial effect of FTY720 on the impaired osteogenesis in BM-MSCs derived from the OVX rats. Furthermore, the results of the present study may also provide a potential therapeutic method for the improvement of bone loss in osteoporosis and alveolar bone resorption in patients with PMO.

\section{Acknowledgements}

The present study was supported by the Chinese National Key Project for Basic Research (grant nos. 2014CB542202) and the National Natural Science Foundations of China (grant nos. 81470631 and 81170982).

\section{References}

1. Rachner TD, Khosla S and Hofbauer LC: Osteoporosis: Now and the future. Lancet 377: 1276-1287, 2011.

2. Liang W, Li X, Li Y, Li C, Gao B, Gan H, Li S, Shen J, Kang J, Ding S, et al: Tongue coating microbiome regulates the changes in tongue texture and coating in patients with post-menopausal osteoporosis of Gan-shen deficiency syndrome type. Int J Mol Med 32: 1069-1076, 2013

3. Khan AA, Morrison A, Hanley DA, Felsenberg D, McCauley LK, O'Ryan F, Reid IR, Ruggiero SL, Taguchi A, Tetradis S, et al: Diagnosis and management of osteonecrosis of the Jaw: A systematic review and international consensus. J Bone Miner Res 30: 3-23, 2015

4. Sato C, Iwasaki T, Kitano S, Tsunemi S and Sano H: Sphingosine 1-phosphate receptor activation enhances BMP-2-induced osteoblast differentiation. Biochem Biophys Res Commun 423: 200-205, 2012

5. Ishii M, Egen JG, Klauschen F, Meier-Schellersheim M, Saeki Y, Vacher J, Proia RL and Germain RN: Sphingosine-1-phosphate mobilizes osteoclast precursors and regulates bone homeostasis. Nature 458: 524-528, 2009.

6. Lotinun S, Kiviranta R, Matsubara T, Alzate JA, Neff L, Lüth A, Koskivirta I, Kleuser B, Vacher J, Vuorio E, et al: Osteoclast-specific cathepsin $\mathrm{K}$ deletion stimulates S1P-dependent bone formation. J Clin Invest 123: 666-681, 2013.

7. Ryu J, Kim HJ, Chang EJ, Huang H, Banno Y and Kim HH: Sphingosine 1-phosphate as a regulator of osteoclast differentiation and osteoclast-osteoblast coupling. EMBO J 25: 5840-5851, 2006.

8. Mandala S, Hajdu R, Bergstrom J, Quackenbush E, Xie J, Milligan J, Thornton R, Shei GJ, Card D, Keohane C, et al: Alteration of lymphocyte trafficking by sphingosine-1-phosphate receptor agonists. Science 296: 346-349, 2002.

9. Venkataraman K, Lee YM, Michaud J, Thangada S, Ai Y, Bonkovsky HL, Parikh NS, Habrukowich C and Hla T: Vascular endothelium as a contributor of plasma sphingosine 1-phosphate. Circ Res 102: 669-676, 2008

10. Poynton AR and Lane JM: Safety profile for the clinical use of bone morphogenetic proteins in the spine. Spine (Phila $\mathrm{Pa}$ 1976) 27 (16 Suppl 1): S40-S48, 2002.

11. Meno-Tetang GM, Li H, Mis S, Pyszczynski N, Heining P, Lowe P and Jusko WJ: Physiologically based pharmacokinetic modeling of FTY720 (2-amino-2 [2-(-4-octylphenyl)ethyl] propane-1,3-diol hydrochloride) in rats after oral and intravenous doses. Drug Metab Dispos 34: 1480-1487, 2006.

12. Sefcik LS, Aronin CE, Awojoodu AO, Shin SJ, Mac Gabhann F, MacDonald TL, Wamhoff BR, Lynch KR, Peirce SM and Botchwey EA: Selective activation of sphingosine 1-phosphate receptors 1 and 3 promotes local microvascular network growth. Tissue Eng Part A 17: 617-629, 2011.

13. Petrie Aronin CE, Shin SJ, Naden KB, Rios PD Jr, Sefcik LS, Zawodny SR, Bagayoko ND, Cui Q, Khan Y and Botchwey EA: The enhancement of bone allograft incorporation by the local delivery of the sphingosine 1-phosphate receptor targeted drug FTY720. Biomaterials 31: 6417-6424, 2010.

14. Petrie Aronin CE, Sefcik LS, Tholpady SS, Tholpady A, Sadik KW, Macdonald TL, Peirce SM, Wamhoff BR, Lynch KR, Ogle RC and Botchwey EA: FTY720 promotes local microvascular network formation and regeneration of cranial bone defects. Tissue Eng Part A 16: 1801-1809, 2010.

15. Turner AS: Animal models of osteoporosis-necessity and limitations. Eur Cell Mater 1: 66-81, 2001.

16. Thompson DD, Simmons HA, Pirie CM and Ke HZ: FDA Guidelines and animal models for osteoporosis. Bone 17 (Suppl 4): S125-S133, 1995.

17. National Research Council of the National Academies: Guide for the Care and Use of Laboratory Animals. 8th edition. The National Academies Press, Washington D.C., 2011.

18. Sims NA, Morris HA, Moore RJ and Durbridge TC: Increased bone resorption precedes increased bone formation in the ovariectomized rat. Calcif Tissue Int 59: 121-127, 1996.

19. Chen HL, Tung YT, Chuang CH, Tu MY, Tsai TC, Chang SY and Chen CM: Kefir improves bone mass and microarchitecture in an ovariectomized rat model of postmenopausal osteoporosis. Osteoporosis Int 26: 589-599, 2015. 
20. Liu Y, Ming L, Luo H, Liu W, Zhang Y, Liu H and Jin Y: Integration of a calcined bovine bone and BMSC-sheet 3D scaffold and the promotion of bone regeneration in large defects. Biomaterials 34 : 9998-10006, 2013.

21. Livak KJ and Schmittgen TD: Analysis of relative gene expression data using real-time quantitative PCR and the 2(-Delta Delta C(T)) method. Methods 25: 402-408, 2001.

22. Miyazaki M, Hardjo M, Masaka T, Tomiyama K, Mahmut N, Medina RJ, Niida A, Sonegawa H, Du G, Yong R, et al: Isolation of a bone marrow-derived stem cell line with high proliferation potential and its application for preventing acute fatal liver failure. Stem Cells 25: 2855-2863, 2007.

23. Wu Y, Zhao RC and Tredget EE: Concise review: Bone marrow-derived stem/progenitor cells in cutaneous repair and regeneration. Stem Cells 28: 905-915, 2010.

24. Wu C, Miron R, Sculean A, Kaskel S, Doert T, Schulze R and Zhang Y: Proliferation, differentiation and gene expression of osteoblasts in boron-containing associated with dexamethasone deliver from mesoporous bioactive glass scaffolds. Biomaterials 32 7068-7078, 2011

25. Zhao Z, Chen Z, Zhao X, Pan F, Cai M, Wang T, Zhang H, Lu JR and Lei M: Sphingosine-1-phosphate promotes the differentiation of human umbilical cord mesenchymal stem cells into cardiomyocytes under the designated culturing conditions. J Biomed Sci 18: 37, 2011

26. Nincheri P, Luciani P, Squecco R, Donati C, Bernacchioni C, Borgognoni L, Luciani G, Benvenuti S, Francini F and Bruni P: Sphingosine 1-phosphate induces differentiation of adipose tissue-derived mesenchymal stem cells towards smooth muscle cells. Cell Mol Life Sci 66: 1741-1754, 2009.
27. Sharma A, Meyer F, Hyvonen M, Best SM, Cameron RE and Rushton N: Osteoinduction by combining bone morphogenetic protein (BMP)-2 with a bioactive novel nanocomposite. Bone Joint Res 1: 145-151, 2012.

28. Sinha KM and Zhou X: Genetic and molecular control of osterix in skeletal formation. J Cell Biochem 114: 975-984, 2013.

29. Jang H, Kim EJ, Park JK, Kim DE, Kim HJ, Sun WS, Hwang S, Oh KB, Koh JT, Jang WG and Lee JW: SMILE inhibits BMP-2-induced expression of osteocalcin by suppressing the activity of the RUNX2 transcription factor in MC3T3E1 cells. Bone 61: 10-18, 2014.

30. Matsuzaki E, Hiratsuka S, Hamachi T, Takahashi-Yanaga F, Hashimoto Y, Higashi K, Kobayashi M, Hirofuji T, Hirata M and Maeda K: Sphingosine-1-phosphate promotes the nuclear translocation of $\beta$-catenin and thereby induces osteoprotegerin gene expression in osteoblast-like cell lines. Bone 55: 315-324, 2013

31. Hashimoto Y, Matsuzaki E, Higashi K, Takahashi-Yanaga F, Takano A,Hirata M and Nishimura F: Sphingosine-1-phosphate inhibits differentiation of $\mathrm{C} 3 \mathrm{H} 10 \mathrm{~T} 1 / 2$ cells into adipocyte. Mol Cell Biochem 401: 39-47, 2015.

32. Komori T: Regulation of osteoblast differentiation by transcription factors. J Cell Biochem 99: 1233-1239, 2006.

33. Kido HW, Bossini PS, Tim CR, Parizotto NA, da Cunha AF, Malavazi I and Renno AC: Evaluation of the bone healing process in an experimental tibial bone defect model in ovariectomized rats. Aging Clin Exp Res 26: 473-481, 2014. 